\title{
DIAGNÓSTICO DA ARBORIZAÇÃO DO BAIRRO SÃO BENEDITO, MUNICÍPIO DE PARNAÍBA, PIAUÍ
}

\author{
DIAGNOSIS OF THE URBAN FOREST OF SÃO BENEDITO, PARNAÍBA, PIAUÍ
}

\author{
Anderson Araújo Rodrigues da Silva ${ }^{1}$, Carlos Henrique Galeno Veras ${ }^{1}$, \\ Jacilene de Carvalho Machado², Juliana Ferreira de Sousa ${ }^{2}$, Maria Aurineide dos Santos Leal' \\ Maria de Jesus da Silva², Maura Rejane de Araújo Mendes ${ }^{3}$
}

\section{RESUMO}

A arborização urbana apresenta diversos benefícios à população, como a melhoria da qualidade do ar, com consequente melhoria da saúde física e mental da população, redução da poluição sonora e visual, além de contribuir para a estabilidade microclimática. Desta forma, a arborização precisa ser planejada. O primeiro passo é a escolha das plantas com melhor adaptação ao ambiente e que não causem danos às residências e vias públicas. O objetivo deste trabalho foi identificar a situação da flora arbustivoarbórea da arborização do Bairro São Benedito, Parnaíba - PI. Para a coleta de dados foi realizado um inventário florístico georreferenciado, que possibilitou analisar aspectos como: situação das raízes nas calçadas, condições dos passeios, afastamento da copa até os lograLdouros, dentre outros. Foram catalogados 919 indivíduos, distribuídos em 47 espécies e 21 famílias. Observou-se o predomínio de Azadirachta indica com $59,6 \%$ dos indivíduos. Trata-se de uma espécie originária da Ásia que atualmente tem recebido preferência da população, entretanto, causa prejuízos, como danos nas calçadas. De modo geral, a arborização do bairro São Benedito foi considerada inadequada, visto que a maioria dos espécimes analisados causam problemas que podem resultar em acidentes, além de não incluir muitas espécies nativas.

Palavras-chave: Espécies arbustivo-arbóreas; Espaço urbano; Planejamento; Abundância de espécies

\begin{abstract}
Urban forest presents several benefits to the population, such as improving air quality, with consequent improvement of the population's physical and mental health; reducing noise and visual pollution; and contributing to microclimate stability. Thus, urban forest should be planned, and the first step is to choose plants adapted to the environment, that do not cause damage to residences and public roads. Therefore, this study aimed to identify shrubs and trees used in the urban forest of São Benedito neighbourhood, in the municipality of Parnaíba, of Piauí state. To data collection, a geo-referenced floristic inventory was realized with attributes placed in a table, which made it possible to analyze some aspects like roots in the sidewalks, ride conditions, treetops removal from outhouse, and other aspects. We catalogued 919 individuals comprising 47 species, distributed in 21 families. Azadirachta indica was the most dominant, encompassing $59.6 \%$ of total individuals. This species is native from Asia and recently received preference of the population, but it causes damage, mainly on the sidewalks. Furthermore, urban forest in São Benedito neighbourhood was consider inappropriate, since most species cause problems that could result in accidents, besides not contain native species.
\end{abstract}

Key words: Shrub-tree species; Urban space; Planning; Plenty of species.

Recebido em 11.02.2019 e aceito em 02.04.2019

1Biólogo Graduado. Formado pela Universidade Estadual do Piauí (UESPI). Parnaíba/PI. Email: andersonarodriges2@gmail.com / carlos-verasphb@outlook.com

2 Bióloga. Graduada. Formada pela UESPI. Parnaíba/PI. Email: jaccy.cocal.cocal@gmail.com/ juliana_sousah@outlook.com/ aurilealphb@hotmail.com/ jizuissilva@gmail.com

3 Bióloga. Doutora. Professora Adjunto IV da UESPI. Parnaíba/PI. Email: maurarejane@phb.uespi.br 


\section{INTRODUÇÃO}

O planejamento urbano consiste em um conjunto de metodologias previamente estudadas com o objetivo de minimizar os impactos negativos causados pela ocupação do homem nos ambientes naturais, como alterações na intensidade de radiação solar, da temperatura, circulação do ar, que estão diretamente relacionados à sensação de bem-estar das pessoas (CEMIG, 2011). Neste sentido, quando bem planejada, a arborização torna-se uma estratégia importante para melhorar a qualidade de vida, sendo considerada o conjunto de vegetação, especialmente arbórea, natural ou cultivada presente em áreas particulares, praças, parques e vias públicas das cidades (GONÇALVES; ROCHA, 2003).

No Brasil, a arborização teve início há aproximadamente um século (CABRAL, 2013), e esteve relacionada ao desenvolvimento econômico e social do país. Infelizmente de forma simultânea ao crescimento da arborização dos centros urbanos, o uso de plantas exóticas de diferentes origens também foi implementado (SANTOS; ANTUNES; BESSEGATTO, 2017) e hoje representam grande parte das espécies utilizadas. Tais espécies podem competir por recursos, como luz, água e nutrientes do solo, com as nativas, pois algumas apresentam maior capacidade de disseminação e podem ocupar novos ambientes mais rapidamente quando comparado às espécies nativas. Portanto, critérios relativos à conservação biológica devem ser considerados para a escolha das espécies, como utilizar plantas nativas da região, tornando-as conhecidas pela população local, que forneçam abrigo e alimentos para a fauna (CASTRO; MORO; ROCHA, 2011).

Outros fatores devem ser considerados para um projeto adequado de arborização, como por exemplo, evitar espécies tóxicas para pessoas e/ou animais que podem causar problemas de saúde pública (FANTINEL et al., 2015); avaliar locais adequados para os plantios que não causem danos às calçadas, às edificações, à fiação elétrica, etc.; considerar a diversidade de espécies, bem como a genética, o projeto não deve contemplar mais de 10\% de indivíduos de uma única espécie; incluir plantas com diferentes estádios de desenvolvimento; plantas com aromas agradáveis e que tragam algum benefício a fauna, entre outros (CEMIG, 2011).

O conhecimento necessário para o sucesso dos projetos de arborização passa pelos estudos e experiências prévias. Neste sentido, trabalhos que enfoquem o resgate do conhecimento das espécies, bem como dos seus benefícios ou prejuízos à população e ao meio ambiente são fundamentais. Para Rocha, Pimentel e Barreto (2012), a importância do inventário está no fato de que através dele pode-se conhecer o patrimônio arbustivo e arbóreo de uma localidade. Assim, nos últimos anos tem crescido o interesse dos pesquisadores das diferentes regiões do Brasil. Destes, a maioria dos estudos concentram-se nas regiões Sul, 
Sudeste e Centro Oeste do País, alguns trabalhos foram realizados por Gonçalves e Rocha (2003) na cidade de São Paulo; Kurihara; Encinas e Paula (2005) na cidade de Brasília; Pires et al. (2010) na cidade de Goiandira. No Nordeste, são registrados trabalhos na Bahia, Pernambuco, Paraíba, Rio Grande do Norte, Sergipe (RODOLFO JúNIOR et al., 2008; ROCHA; PIMENTEL; BARRETO, 2012; SILVA; RODRIGUES; LUCENA, 2017; JUSTINO et al. 2018) e no Piauí (BARBOSA et al., 2015; CARVALHO; NOGUEIRA; LEMOS, 2016; SILVA; RIBEIRO, 2017).

Portanto, este trabalho objetivou identificar a flora arbustivo-arbórea utilizada na arborização do Bairro São Benedito, Parnaíba - PI, bem como diagnosticar os possíveis conflitos causados pelas plantas nas vias urbanas, e assim, fornecer dados essenciais para delinear estratégias de programas futuros que envolvam o planejamento da arborização.

\section{MATERIAL E MÉTODOS}

\section{Localização e descrição da área}

O município de Parnaíba está localizado na microrregião do Litoral Piauiense, compreendendo uma área irregular aproximada de $434.000 \mathrm{~km}^{2}$ e tendo como limites: ao norte o município de Ilha Grande e o oceano Atlântico, ao sul Buriti dos Lopes e Cocal, a leste Luís Correia, e a oeste o estado do Maranhão (IBGE, 2017). O município tem como coordenadas geográficas $\left(02^{\circ} 54^{\prime} 17^{\prime \prime} S 41^{\circ} 46^{\prime} 36^{\prime \prime} \mathrm{W}\right)$, apresenta temperaturas mínimas de $20^{\circ} \mathrm{C}$ e máximas de $32^{\circ} \mathrm{C}$ e clima quente tropical (AGUIAR, 2004). A vegetação está caracterizada por áreas de transição entre caatinga/cerrado caducifólio e floresta ciliar de carnaúba/caatinga de várzea (AGUIAR, 2004). O bairro São Benedito que foi o foco deste estudo localiza-se na região norte da cidade (Figura 1). Possui uma população de 2.691 habitantes (CENSO, 2010), onde está situado o Campus da Universidade Estadual do Piauí - UESPI.

\section{Coleta e tratamento dos dados}

Com a ajuda de um mapa, foi realizado o inventário florístico do tipo censo das plantas com hábitos arbustivo e/ou arbóreo, percorrendo todas as ruas do bairro, no período de maio a agosto de 2017. A coleta de informações no campo contou com ajuda de um GPS (GARMIM 60CSx) para o georreferenciamento das espécies. As coletas botânicas seguiram técnicas usuais adotadas por Mori et al. (1989). Em seguida, os espécimes foram levados ao laboratório de biologia da Universidade Estadual do Piauí, campus Alexandre Alves de 
Oliveira onde foram feitas as primeiras identificações. As espécies foram classificadas em famílias de acordo com o sistema do Angiosperm Phylogeny Group (APG) IV (2016).

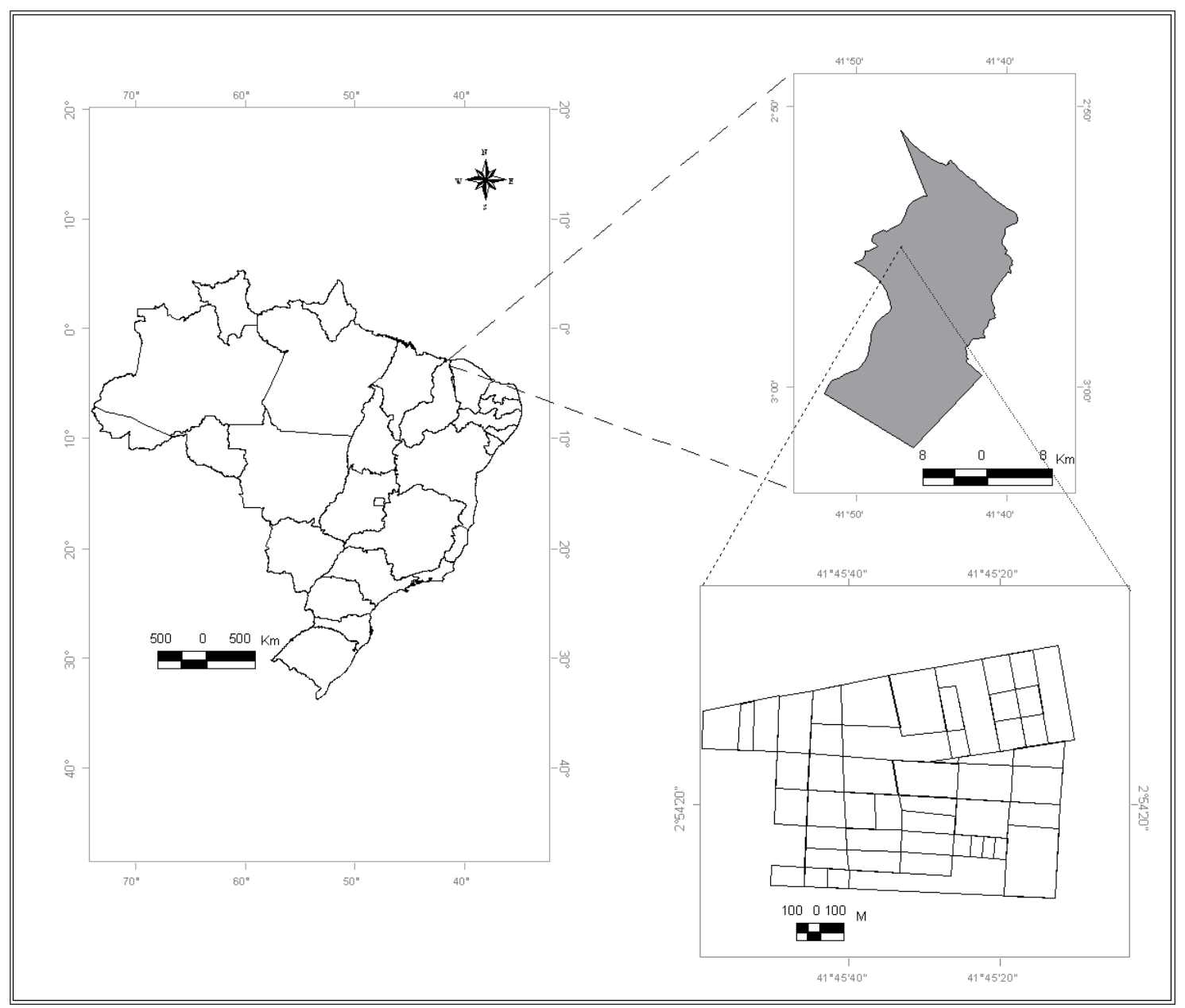

Figura 1. Localização do Bairro São Benedito, Parnaíba, Piauí

Figure 1. Map showing the neighbourhood São Benedito, munipality of Parnaíba, State of Piauí

O inventário florístico foi seguido da análise das condições dos passeios. A coleta de dados seguiu os trabalhos de Rocha, Pimentel e Barreto (2012), seguida por Carvalho, Nogueira e Lemos (2016), incluindo os seguintes parâmetros: identificação da espécie, relação das raízes nas calçadas (sendo, $0=$ sem danos, $1=$ calçadas com rachaduras foram consideradas danos leves, 2 = quando as rachaduras provocavam fendas grandes que danificavam o passeio, os danos eram médios, 3 = quando o concreto das calçadas eram retirados, podendo inviabilizar o trânsito de idosos e cadeirantes, os danos eram graves); largura dos passeios $(0=$ até $1 \mathrm{~m}, 1>1$ a $1,5 \mathrm{~m}, 2>1,5$ a 2,5, $3>2,5 \mathrm{~m})$; diâmetro à altura do peito (DAP) $(0=$ até $0,32 \mathrm{~m}, 1>0,32$ a 0,48, $2>0,48$ a 0,8 $\mathrm{m}, 3>0,8 \mathrm{~m})$; distância das árvores até as edificações e até os logradouros $(0=$ sem afastamento, $1<1,5 \mathrm{~m}, 2=1,5$ a 3 
m, $3>3 \mathrm{~m}$ ); relação das árvores com a fiação elétrica ( 0 = sem toque na fiação, 1 = fiação abaixo da copa, 2 = fiação no meio da copa, 3 = fiação acima da copa); avanço das copas nos logradouros ( $0=$ sem avanço, $1<0,5 \mathrm{~m}, 2=0,5$ a $1 \mathrm{~m}, 3>1 \mathrm{~m})$; avanço das copas nas edificações ( 0 = sem avanço, 1 = avanço, mas sem toque, 2 = avanço com contato, $3=$ entrelaça nas edificações) e altura da primeira bifurcação da planta $(0=$ até $1 \mathrm{~m}, 1>1$ a 1,5 $\mathrm{m}, 2>1,5$ a $2 \mathrm{~m}, 3>2 \mathrm{~m})$.

Os mapas da área de estudo foram realizados utilizando o software ArcView 3.2 e incluíram os dados registrados no campo, bem como polígonos do bairro obtidos do Google Earth Pro.

\section{RESULTADOS E DISCUSSÃO}

Foram catalogados 919 indivíduos do componente arbustivo-arbóreo, distribuídos em 47 espécies, 21 famílias e 44 gêneros (Tabela 1). O número de espécies registradas foi superior ao encontrado por Carvalho, Nogueira e Lemos (2016), que citaram 19 espécies em outro bairro da cidade de Parnaíba (bairro Nova Parnaíba). Entretanto, foi semelhante no que refere à dominância de poucas espécies utilizadas na arborização. Azadirachta indica (Neem), representou 59,6\% e 45\% dos indivíduos amostrados nos bairros São Benedito e Nova Parnaíba, respectivamente. Azadirachta indica também é dominante em outros levantamentos de arborização no Piauí (BARBOSA et al., 2015; SILVA; RIBEIRO, 2017). Trata-se de uma espécie exótica, originária do sudoeste da Ásia, sendo atualmente muito utilizada na ornamentação de praças, jardins, ruas e avenidas, principalmente pelo fato de proporcionar sombra, crescimento rápido e proteção contra pragas (MOSSINI, 2006). Entretanto, a espécie pode causar impactos ecológicos negativos importantes que devem ser levados em consideração, como redução da biodiversidade, por supressão de outras espécies através de sua alelopatia e dominância (INSTITUTO HÓRUS, 2019).

Tabela 1. Espécies do componente arbustivo-arbóreo utilizadas na arborização do bairro São Benedito, Parnaíba, Piauí

Table 1. Species of shrubs and trees used in afforestation of the Bairro São Benedito, Parnaíba, Piauí

\begin{tabular}{|c|c|c|c|c|}
\hline Família/espécie & Nome comum & Hábito & Origem & Total \\
\hline ANACARDIACEAE & & & & \\
\hline Anacardium occidentale L. & Cajueiro & Arbóreo & Nativa & 5 \\
\hline Mangifera indica L. & Mangueira & Arbóreo & Exótica & 8 \\
\hline $\begin{array}{l}\text { Schinus terebinthifolius Raddi } \\
\text { ANNONACEAE }\end{array}$ & Aroeira-vermelha & Arbóreo & Nativa & 1 \\
\hline Annona squamosa L. & Ata/fruta-do-conde & Arbustivo & Exótica & 2 \\
\hline
\end{tabular}




\begin{tabular}{|c|c|c|c|c|}
\hline Família/espécie & Nome comum & Hábito & Origem & Total \\
\hline \multicolumn{5}{|l|}{ APOCYNACEAE } \\
\hline Nerium oleander L. & Espirradeira & Arbustivo & Exótica & 3 \\
\hline Plumeria pudica Jacq. & Buquê-de-noiva & Arbustivo & Exótica & 12 \\
\hline $\begin{array}{l}\text { Thevetia peruviana (Pers.) K. Schum. } \\
\text { ARECACEAE }\end{array}$ & Chapéu-de-napoleão & Arbustivo & Exótica & 1 \\
\hline Cocos nucifera L. & Coqueiro & Arbóreo & Exótica & 2 \\
\hline Copernicia prunifera (Mill.) H.E. Moore & Carnaúba & Arbóreo & Nativa & 5 \\
\hline Desconhecida 1 & - & Arbustivo & - & 1 \\
\hline Roystonea sp. & Palmeira-imperial & Arbóreo & - & 2 \\
\hline Phoenix roebelenii O'Brien & Palmeira-fênix & Arbustivo & Exótica & 6 \\
\hline $\begin{array}{l}\text { Veitchia merrillii (Becc.) H.E. Moore } \\
\text { BIGNONIACEAE }\end{array}$ & Palmeira-havaí & Arbustivo & Exótica & 15 \\
\hline Tabebuia cf. rosea (Bertol.) A.DC. & Ipê-rosa & Arbóreo & Nativa & 16 \\
\hline $\begin{array}{l}\text { Spathodea campanulata P. Beauv. } \\
\text { CACTACEAE }\end{array}$ & Espatódea & Arbóreo & Exótica & 1 \\
\hline Pereskia bleo (Kunth) DC. & Cacto-rosa & Arbustivo & Exótica & 2 \\
\hline $\begin{array}{l}\text { Pereskia grandifolia Haw. } \\
\text { CARICACEAE }\end{array}$ & Rosa-madeira & Arbustivo & Nativa & 2 \\
\hline $\begin{array}{l}\text { Carica papaya } \mathrm{L} . \\
\text { CASUARINACEAE }\end{array}$ & Mamão & Arbustivo & Exótica & 2 \\
\hline $\begin{array}{l}\text { Casuarina sp. } \\
\text { CECROPIACEAE }\end{array}$ & Casuarina & Arbóreo & - & 42 \\
\hline $\begin{array}{l}\text { Cecropia sp. } \\
\text { CHRYSOBALANACEAE }\end{array}$ & Embaúba & Arbóreo & - & 2 \\
\hline $\begin{array}{l}\text { Licania tomentosa (Benth.) Fritsch } \\
\text { COMBRETACEAE }\end{array}$ & Oiti & Arbóreo & Nativa & 47 \\
\hline $\begin{array}{l}\text { Terminalia catappa } \mathrm{L} . \\
\text { FABACEAE }\end{array}$ & Amendoeira & Arbóreo & Exótica & 17 \\
\hline Bauhnia sp. & Pata-de-vaca & Arbustivo & - & 4 \\
\hline Paubrasilia echinata Lam. & Pau-Brasil & Arbóreo & Nativa & 2 \\
\hline Cassia fistula $\mathrm{L}$. & Chuva-de-ouro & Arbóreo & Exótica & 9 \\
\hline Cassia sp. & Cassia & Arbóreo & - & 2 \\
\hline Clitoria fairchildiana R.A. Howard & Clitoria & Arbóreo & Exótica & 8 \\
\hline Caesalpinia pulcherrima (L.) Sw. & Flamboyanzinho & Arbustivo & Exótica & 2 \\
\hline Delonix regia (Bojer ex Hook.) Raf. & Flamboyant & Arbóreo & Exótica & 11 \\
\hline Libidibia ferrea (Mart. ex Tul.) L.P. Queiroz & Pau-ferro/jucá & Arbóreo & Nativa & 3 \\
\hline Pithecellobium dulce (Roxb.) Benth. & Mata-fome & Arbóreo & Exótica & 5 \\
\hline Poincianella bracteosa (Tul.) L.P. Queiroz & Catingueira & Arbóreo & Nativa & 2 \\
\hline Erythrina sp. & Mulungo & Arbóreo & - & $\overline{7}$ \\
\hline $\begin{array}{l}\text { Prosopis sp. } \\
\text { LECYTHIDACEAE }\end{array}$ & Algaroba-amarela & Arbóreo & - & 2 \\
\hline $\begin{array}{l}\text { Couroupita guianensis Aubl. } \\
\text { MALVACEAE }\end{array}$ & Sapucaia & Arbóreo & Nativa & 7 \\
\hline Hibiscus sp. & Algodão & Arbóreo & - & 4 \\
\hline $\begin{array}{l}\text { Pachira aquatica Aubl. } \\
\text { MELIACEAE }\end{array}$ & Paquira-aquática & Arbóreo & Nativa & 24 \\
\hline $\begin{array}{l}\text { Azadirachta indica A. Juss. } \\
\text { MORACEAE }\end{array}$ & Neem & Arbóreo & Exótica & 548 \\
\hline $\begin{array}{l}\text { Ficus benjamina L. } \\
\text { MORINGACEAE }\end{array}$ & Figueira & Arbóreo & Exótica & 27 \\
\hline Moringa oleifera Lam. & Moringa & Arbóreo & Exótica & 3 \\
\hline Eucalyptus sp. & Eucalipto & Arbóreo & - & 1 \\
\hline Psidium guajava L. & Goiabeira & Arbóreo & Nativa & 1 \\
\hline $\begin{array}{l}\text { Syzygium malaccense (L.) Merr. \& L.M. Perry } \\
\text { PODOCARPACEAE }\end{array}$ & Jambeiro & Arbóreo & Exótica & 31 \\
\hline $\begin{array}{l}\text { Podocarpus sp. } \\
\text { RUBIACEAE }\end{array}$ & Podocarpos & Arbustivo & - & 14 \\
\hline $\begin{array}{l}\text { Morinda citrifolia L. } \\
\text { SAPOTACEAE }\end{array}$ & Noni & Arbustivo & Exótica & 1 \\
\hline Manilkara zapota (L.) P. Royen & Sapotizeiro & Arbóreo & Exótica & 1 \\
\hline Pouteria sp. & & Arbóreo & - & 1 \\
\hline
\end{tabular}


Outras espécies que figuraram entre as mais abundantes foram Licania tomentosa (47 indivíduos), Casuarina sp. (42), Syzygium malaccense (31), Ficus benjamina L. (27) e Pachira aquatica (24) (Figura 2), demonstrando que as seis espécies mais frequentes somam $78,2 \%$ do total de indivíduos. O ideal da arborização, quando planejada, é incluir diversidade de espécies, as densidades não deveriam ultrapassar 30\% de uma única família, 20\% de um único gênero e 10\% de uma espécie (CEMIG, 2011). A família Fabaceae se destacou como a mais representativa no número de espécies (13), possivelmente por ser bem distribuída na região Nordeste. Com relação à frequência de indivíduos, a família Meliaceae $(59,6 \%)$ também não atende ao percentual ideal do número de indivíduos citado acima. Vários problemas podem ocorrer pelo plantio excessivo de uma ou poucas espécies, como diminuição da oferta de alimentos para animais, monotonia estética na paisagem, maior suscetibilidade aos ataques de pragas, além da desvalorização do patrimônio natural do local (SILVA; RODRIGUES; LUCENA, 2017).

A distribuição das espécies entre as ruas do bairro (Figura 2), refletiu falta de planejamento da arborização. Segundo Cabral (2013), as árvores não devem ser plantadas sem que haja um planejamento prévio que considere as características das espécies, bem como as características urbanas, para evitar que na fase adulta as mesmas causem problemas, o tem se tornado um grande desafio para a administração municipal que tem a competência de promover e executar as ações relacionadas à arborização.

Os problemas entre a arborização e as calçadas são conflitos comuns causados pelas espécies utilizadas no bairro São Benedito. Do total, 59\% dos indivíduos causam algum dano. Azadirachta indica apresentou maior índice de danos leves nas calçadas e Licania tomentosa foi a responsável pelos mais graves. Com a mesma metodologia, Carvalho, Nogueira e Lemos (2016), encontraram maior número de indivíduos que provocam algum dano (74\%), em outro bairro de Parnaíba. Estes problemas são comuns e citados por outros autores (por exemplo, GONÇALVES; ROCHA, 2003; PIRES et al., 2010). O bairro São Benedito apresenta fiação principalmente de baixa tensão, $75,9 \%$ das plantas não apresentavam contato nenhum com a fiação, enquanto cerca de $24,1 \%$ apresentaram problemas, tocando na copa, ou passando da mesma, podendo ocasionar sérios incidentes pelo perigo associado ao entrelaçamento entre a vegetação e a fiação. Vale ressaltar que alguns indivíduos eram plantas jovens, não mantendo contato no momento da amostragem, mas com potencial de causar danos no futuro. Dessa forma, problemas dessa natureza podem ser evitados com o prévio conhecimento das espécies plantadas, diminuindo os riscos a população (CABRAL, 2013), ou com planejamento adequado da própria fiação, através de alternativas técnicas para as redes de distribuição, como projetos especiais de 
compatibilização (CEMIG, 2011). Por outro lado, se a vegetação já está no lugar inadequado, podem ser programadas podas emergenciais para condução do crescimento das árvores, ou mesmo removê-las, abrindo espaço para o plantio de uma espécie adequada (CEMIG, 2011).

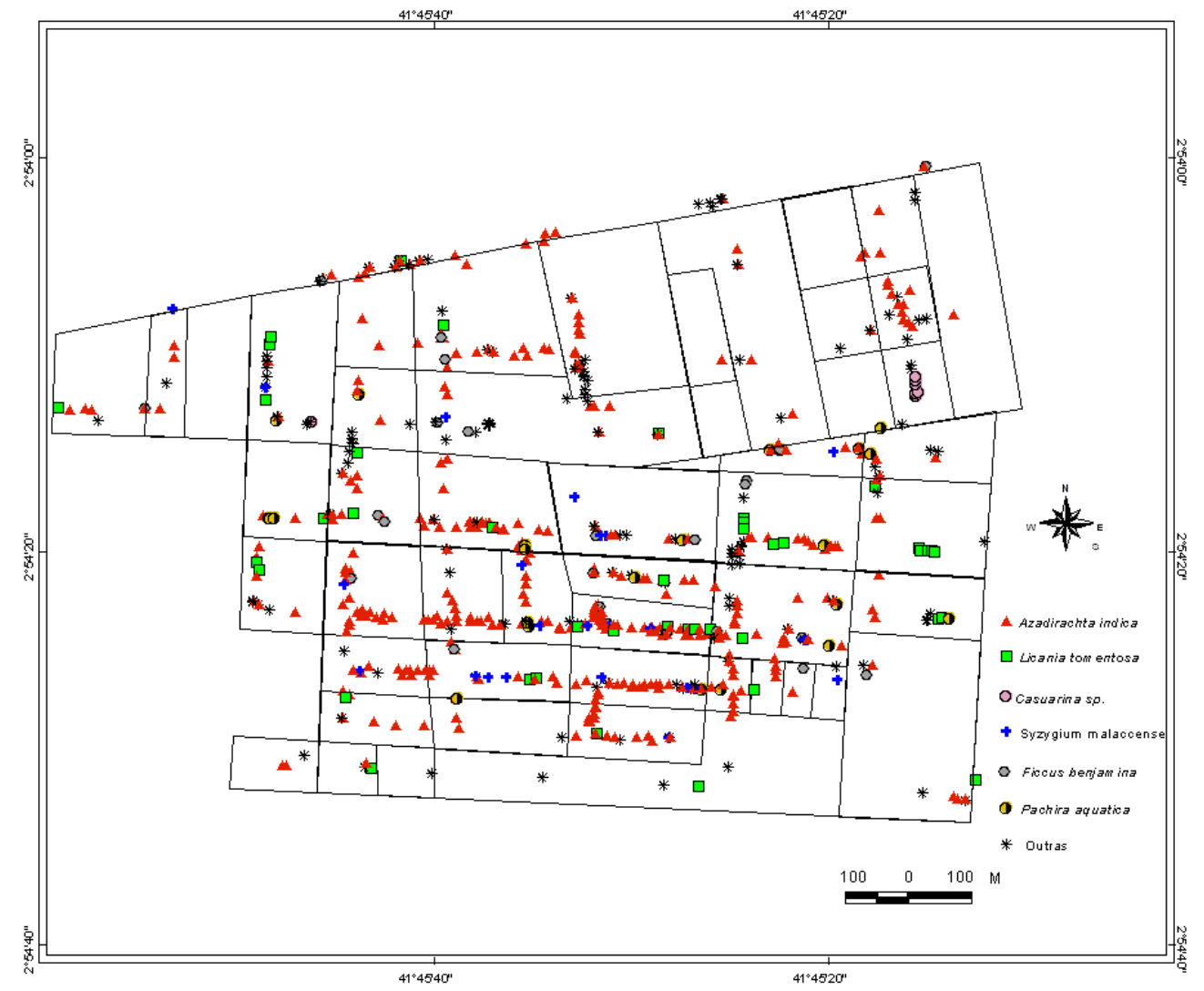

Figura 2. Mapa de distribuição dos indivíduos do componente arbustivo-arbóreo identificados nas ruas do Bairro São Benedito, Parnaíba, Piauí

Figure 2. Map showing the distribution of shrubs and trees individuals identified on the Bairro São Benedito, Parnaíba, Piauí

De modo geral, as plantas utilizadas na arborização do Bairro São Benedito apresentam distância das edificações, 40\% dos indivíduos estavam localizados a mais de três metros, enquanto a maioria não apresentou afastamento dos logradouros, ou seja, até a pista de rolamento (Figura 3). Com relação a largura dos passeios, $64,5 \%$ dos indivíduos estavam plantados em passeios maiores de 2,5 m. Resultados semelhantes aos registrados por Rocha, Pimentel e Barreto (2012), Carvalho, Nogueira e Lemos (2016), registraram mais de $23 \%$ e 60\% dos indivíduos arbóreos em calçadas largas (acima de 2,5 m), em Recife e em outro bairro de Parnaíba, respectivamente. Quando analisado se as copas avançavam sob a pista de rolamento, apenas $9 \%$ dos indivíduos avançavam mais de 1,5 m, portanto, o bairro não apresenta potencial de problemas com trânsito de veículos. $E$ também, a maioria das árvores 
não apresentou avanço das copas nas edificações (67\%), sendo que apenas $4 \%$ dos indivíduos arbóreos as copas entrelaçavam e faziam contato com estruturas das edificações.

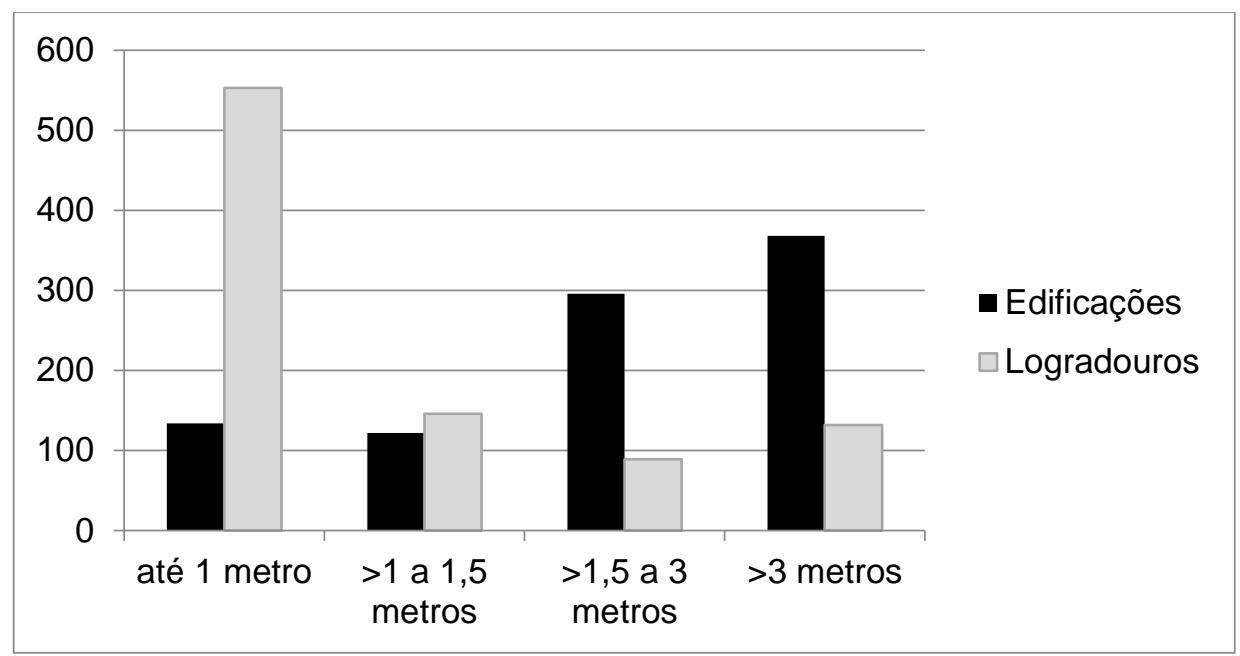

Figura 3. Disposição do afastamento do componente arbustivo-arbóreo até as edificações e logradouros no bairro São Benedito, Parnaíba, Piauí

Figure 3. Histogram indicating the distance of the shrubs and trees individuals to the buildings and public spaces in the Bairro de São Benedito, Parnaíba, Piauí.

Houve predomínio das espécies arbóreas (71,2\%). Considerando todas as plantas amostradas, a maioria das espécies esteve dentro das duas últimas classes de DAP, 0,48 a 0,8 m e > 0,8 m (Figura 4), com maior contribuição de Azadirachta indica. Carvalho, Nogueira e Lemos (2016), que utilizaram a mesma metodologia, registraram predominância de indivíduos nas mesmas classes. O destaque também para a segunda classe nesse trabalho pode ser explicado pela inclusão das arbustivas como Bauhinia sp., Caesalpinia pulcherrima, dentre outras, além de indivíduos jovens de espécies arbóreas, especialmente de Azadirachta indica.

Com relação à primeira bifurcação, 41,2\% das plantas avaliadas apresentaram até $1 \mathrm{~m}$. As outras três classes consideradas, de 1 até $1,5 \mathrm{~m},>1,5$ até $2 \mathrm{~m}$ e $>2 \mathrm{~m}$, incluíram 24,9, 17,1 e $16,8 \%$, respectivamente. Segundo Rodolfo Júnior et al. (2008), quando a primeira bifurcação é baixa e voltada para o passeio pode causar problemas aos pedestres, bem como causar transtornos para os transportes, quando voltada para rua. Assim, de acordo com os autores, deve ser conduzido o crescimento dessas plantas ainda jovens. 


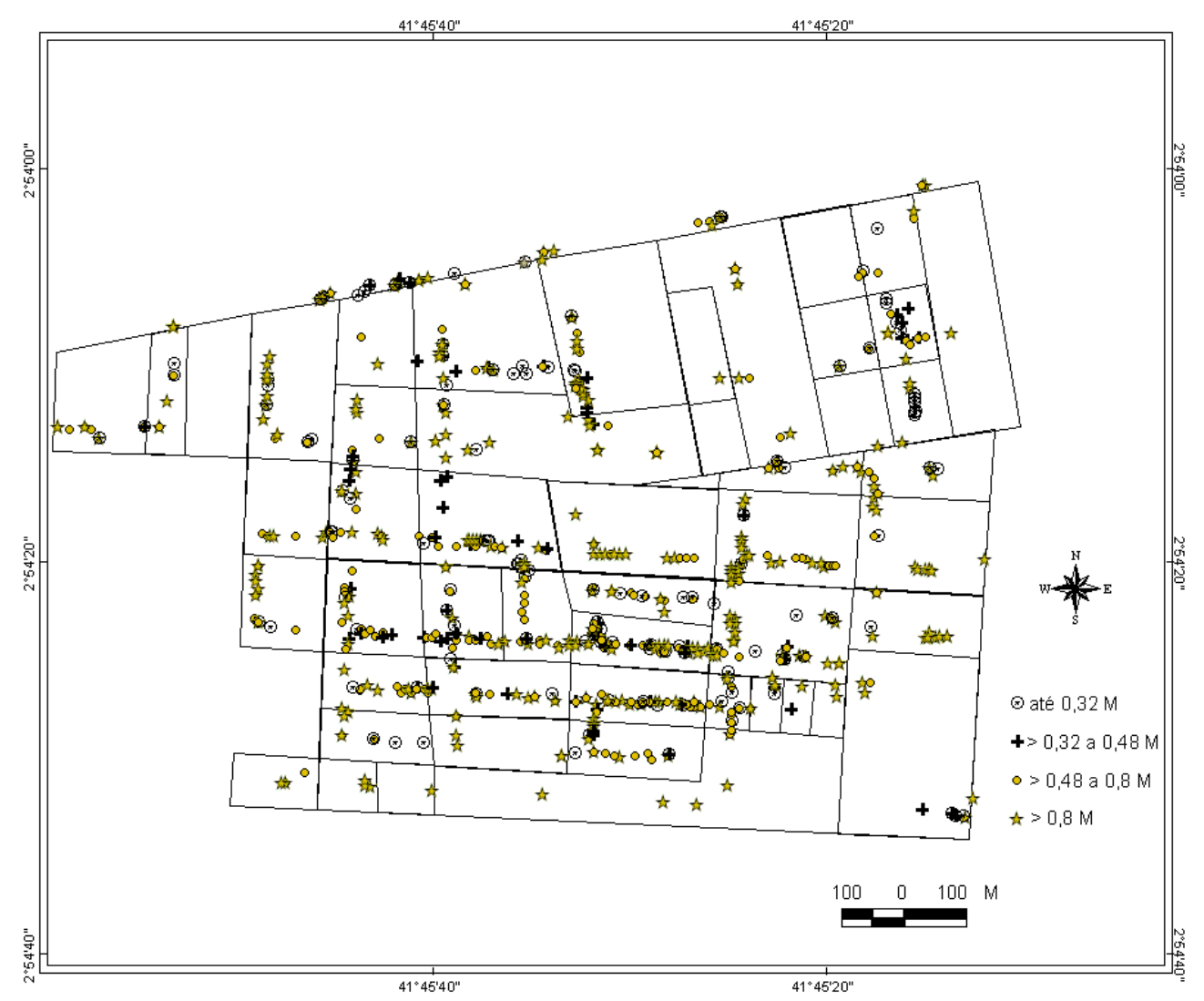

Figura 4. Mapa com a disposição e proporções do DAP no bairro dos São Benedito, Parnaíba, Piauí Figure 4. Map showing the DBH dispositions and proportions in the Bairro de São Benedito, Parnaíba, Piauí

A maioria das espécies registradas e identificadas no bairro São Benedito são exóticas (Tabela 1), padrão semelhante ao registrado em muitos trabalhos de arborização no Brasil (por exemplo: ROCHA; PIMENTEL; BARRETO, 2012; CARVALHO; NOGUEIRA; LEMOS, 2016; SILVA; RIBEIRO, 2017; JUSTINO et al. 2018). Destas, algumas são tóxicas, como Nerium oleander e Thevetia peruviana, a primeira com propriedades cardiotóxicas, podendo causar convulsões, e a segunda espécie podendo causar irritação na pele e olhos (LOPES; RITTER; RATES, 2009; FANTINEL et al., 2015).

\section{CONCLUSÕES}

O Bairro São Benedito dispõe de um grande número de plantas, distribuído em 47 espécies, que diferem no impacto causado nos passeios e fiação elétrica. A espécie que provocou maiores danos às calçadas foi Licania tomentosa causando grandes fissuras capazes de retirar o concreto das calçadas e dificultar o trânsito de pedestres. Não foram 
registrados conflitos relacionados pela bifurcação das árvores, nem pelo avanço das copas à pista de rolamento.

Ocorre também uma grande quantidade de plantas exóticas, principalmente de Azadirachta indica, que totalizou 59,6\% dos indivíduos. Dessa forma, torna-se necessário um melhor planejamento urbano com suspensão do uso de espécies exóticas e valorização das nativas.

\section{REFERÊNCIAS}

AGUIAR, R. B. Projeto cadastro de fontes de abastecimento por água subterrânea, Estado do Piauí: diagnóstico do Município de Parnaíba. Fortaleza: CPRM - Serviço Geológico do Brasil, 2004.

ANGIOSPERM PHYLOGENY GROUP (APG IV). An update of the Angiosperm Phylogeny Group classification for the orders and families of flowering plants: APG IV. Botanical Journal of the Linnean Society, Londres, v. 161, n. 20, p. 105-121, 2016.

BARBOSA, R. P.; PORTELA, M. G. T.; MACHADO, R. R. B.; SÁ, A. S. Arborização da avenida Deputado Ulisses Guimarães, bairro Promorar, Zona Sul de Teresina - PI. Revista da Sociedade Brasileira de Arborização Urbana, Piracicaba, v.10, n.2, p. 78-89, 2015.

CABRAL, P. I. D. Arborização urbana: problemas e benefícios. Revista Especialize On-line IPOG, Goiania, v. 1, n. 6, p. 1-15, 2013.

CARVALHO, L. A.; NOGUEIRA, J. F.; LEMOS, J. R. Inventário da arborização de um bairro da Cidade de Parnaíba - Piauí, com a utilização de um sistema de informação geográfica. Revista da casa da Geografia de Sobral, Sobral, v. 18, n. 1, p. 100-118, 2016.

CASTRO, A. S. F.; MORO, M. F.; ROCHA, F. C. L. Plantas dos espaços livres da Reitoria da Universidade de Fortaleza (UNIFOR), Ceará, Brasil. Revista Brasileira de Biociência, Porto Alegre, v. 9, n. 1, p. 126-129, 2011.

COMPANHIA ENERGÉTICA DE MINAS GERAIS (CEMIG). Manual de arborização. Belo Horizonte, 2011. $112 \mathrm{p}$.

CENSO, 2010. POPULAÇÃO. Disponível em: <http://populacao.net.br/>. Acesso em: 01 de nov. 2017.

FANTINEL, R. A.; PONS, P. G.; ROSA, D. C.; CAVALHEIRO, R.; CECHIN, N. F. Identificação e quantificação de espécies com princípios tóxicos ou alérgicos na arborização de ruas e avenidas São Gabriel - RS. Revista Brasileira de Arborização Urbana, Piracicaba, v.10, n.1, p. 61-70, 2015.

GONÇALVES, S.; ROCHA F. T. Caracterização da arborização urbana do bairro de vila Maria Baixa. ConScientiae Saúde, São Paulo, n. 2, p. 67-75, 2003.

INSTITUTO BRASILEIRO DE GEOGRAFIA E ESTATÍSTICA (IBGE). Disponível em: <https:// cidades.ibge.gov.br/brasil/pi/parnaiba/panorama>. Acesso em: 15 de jul. 2017. 
INSTITUTO HÓRUS. Base de dados nacional de espécies exóticas invasoras I3N Brasil, Instituto Hórus de Desenvolvimento e Conservação Ambiental. Disponível em: <http://i3n.institutohorus.org.br/www/>. Acesso em: 20 mar. 2019.

JUSTINO, S. T. P.; MORAIS, Y. Y. G. A.; NASCIMENTO, A. K. A.; SOUTO, P. C. Composição e georreferenciamento da arborização urbana no Distrito de Santa Gertrudes, em Patos - Pb. Revista da Sociedade Brasileira de Arborização Urbana, Curitiba, v. 13, n. 3, p. 24-35, 2018.

KURIHARA, D. L, ENCINAS, J. I.; PAULA, J. E. Levantamento da arborização do Campus da Universidade de Brasília. Revista Cerne, Lavras, v. 11, n. 2, p. 127-136, 2005.

LOPES, R. K.; RITTER, M. R.; RATES, S. M. K. Revisão das atividades biológicas e toxicidade das plantas ornamentais mais utilizadas no Rio Grande do Sul, Brasil. Revista Brasileira de. Biociência, Porto Alegre, v. 7, n. 3, p. 305-315, 2009.

MORI, A. S.; SILVA, L. A. M.; LISBOA, G.; CORANDIN, L. Manual de manejo do herbário fanerogâmico. $2^{\underline{a}}$ ed. Centro de Pesquisas do Cacau: Ilhéus, 1989.

MOSSINI, S. A. G. Efeitos de extratos de Azadirachta indica A. Juss (Meliaceae) na produção de micotoxinas e na morfologia de fungos toxigênicos. 49f. Tese (Doutorado em Ciências Biológicas) - Universidade Estadual de Maringá, Paraná, 2006.

PIRES, N. A. M. T.; MELO, M. S.; OLIVEIRA, D. E.; SANTOS, S. X. Arborização urbana do município de Goiandira/Go - Caracterização quali-quantitativa e propostas de manejo. Revista Brasileira de Arborização Urbana, Piracicaba, v. 5, n. 3, p.185-205, 2010.

Prefeitura Municipal de João Pessoa - Secretaria de Meio Ambiente. Cartilha de Arborização Urbana. 3.ed. João Pessoa-Paraíba: SEMAM, 2011.

ROCHA, R.; PIMENTEL, R. M. M.; BARRETO, R. C. Censo da arborização viária de um bairro da cidade do Recife, Pernambuco, com a utilização de um sistema de informação geográfica. Revista Brasileira de Geografia Física, Recife, v. 5, n. 2. p. 285-301, 2012.

RODOLFO, J. F.; MELO, R. R.; CUNHA, T. A.; STANGERLIN, D. M. Análise da arborização urbana em bairros da cidade de Pombal no Estado da Paraíba. Revista Brasileira de Arborização Urbana, Piracicaba, v.3, n.4, p.3-19, 2008.

SANTOS, R. C.; ANTUNES, L.; BESSEGATTO, D. Espécies exóticas invasoras na arborização urbana de vias públicas de Sananduva/RS. Revista Brasileira de Arborização Urbana, Piracicaba, v.12, n.2, p. 39-47, 2017.

SILVA, I. C.; RIBEIRO, V. T. Arborização urbana na cidade de Paulistana-Pi: Uma análise das praças públicas. Revista Brasileira de Arborização Urbana, Piracicaba, v. 12, n. 1, p. 7991, 2017.

SILVA, R. F. L.; RODRIGUES, J. S.; LUCENA, M. F. A. Avaliação das espécies vegetais utilizadas na arborização em canteiros e praças de Tuparetama, Pernambuco, Nordeste do Brasil. Revista Brasileira de Arborização Urbana, Piracicaba, v. 12, n. 1, p. 132-141, 2017. 